\section{A new method for placement of covered colorectal stents in the proximal colon using double balloon enteroscopy}

A 62-year-old patient was admitted for a persisting colocutaneous fistula in the transverse colon following relocation of a double-barreled anus praetor transversalis and resultant stenosis. Because of the presence of a frozen abdomen, owing to multiple previous surgeries, we opted for endoscopic intervention. To safely and easily place a routine, covered colorectal stent, in the absence of appropriate, available through-the-scope devices and in the presence of the excessive postsurgical scarring with fixed and adherent loops of the pelvic part of proximal transverse colon, we used the double-balloon enteroscopy procedure with a technical modification. A Savary guide wire (Cook Medical, Bloomington, Indiana, USA) was advanced through the working channel of an enteroscope over the stenosis in the area of the transverse colon. After completing threading and retracting the overtube maximally, the enteroscope was removed from the overtube. Then the overtube was cut for three-quarters of its circumference in the area of the anus ( Fig. 1). Care was taken that the pressure line for the balloon remained intact. It was now possible to advance the covered colorectal stent via the Savary guide wire and through the overtube ( Fig. 2), under X-ray guidance, up to the stenosis and open the stent in this position ( Fig. 3). A similar technique has been described by Fähndrich et al. for endoscopic intervention using double balloon enteroscopy in the bile duct region after Roux-en-Y reconstruction [1].
This is the first report of the use of an overtube as a technical modification in cases requiring covered colorectal stents. This method allowed safer placement of such a stent in a segment of the proximal colon with straightening and shortening of the initial length of the stent and using standard enteroscopic products, with improved splinting and resultant decreased risk of perforation.

\section{Endoscopy_UCTN_Code_TTT_1AQ_2AG}

Competing interests: None

\section{Fähndrich, M. Sandmann, M. Heike Klinikum Dortmund - Gastroenterologie, Dortmund, Germany}

\section{Reference}

1 Fähndrich M, Sandmann M, Heike M. A facilitated method for endoscopic interventions at the bile duct after Roux-en-Y reconstruction using double balloon enteroscopy. Z Gastroenterol 2008; 46: 335-338

\section{Bibliography}

DOI $10.1055 / \mathrm{s}-0030-1255895$

Endoscopy 2011; 43: E23

(c) Georg Thieme Verlag KG Stuttgart - New York . ISSN 0013-726X

\section{Corresponding author \\ M. Fähndrich}

Klinikum Dortmund - Gastroenterologie

Beurhausstr. 11

Dortmund 44137

Germany

Fax: +4923195320840

martin.faehndrich@klinikumdo.de

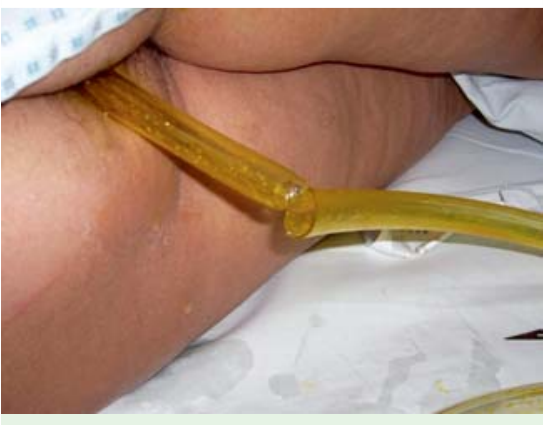

Fig. 1 The overtube cut around three-quarters of its circumference in the area of the anus.

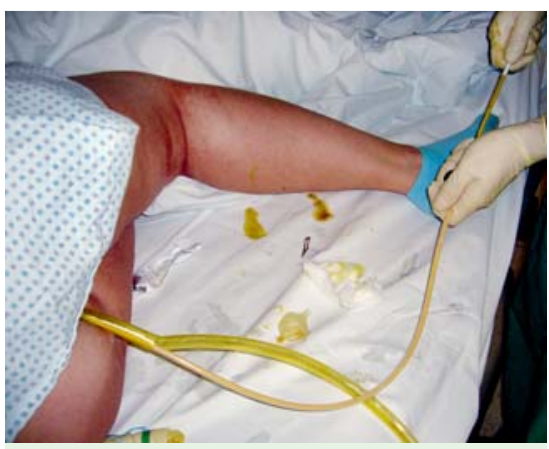

Fig. 2 Placement of the covered colorectal stent via the Savary guide wire and through the overtube.

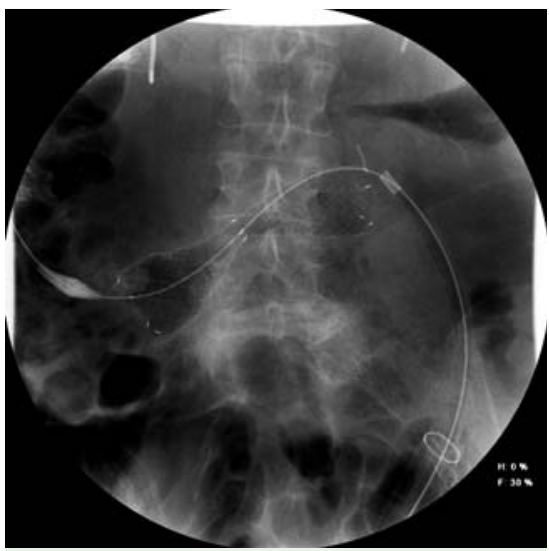

Fig. 3 The covered colorectal stent seen within the proximal colon. 